\title{
The Contribution of Four Immunogenetic Markers for Predicting Persistent Activity in Patients with Recent-Onset Rheumatoid Arthritis or Undifferentiated Arthritis
}

\author{
Sonsoles Reneses, ${ }^{1}$ Antonio Fernández-Suárez, ${ }^{2}$ Maria F. González-Escribano, ${ }^{3}$ \\ Luis Pestana, ${ }^{4}$ and Alicia García ${ }^{1}$ \\ ${ }^{1}$ Department of Rheumatology, Virgen del Rocio University Hospital, 41013 Seville, Spain \\ ${ }^{2}$ Biotechnology Area, Alto Guadalquivir Hospital, 23740 Andújar, Spain \\ ${ }^{3}$ Department of Immunology, Virgen del Rocío University Hospital, 41013 Seville, Spain \\ ${ }^{4}$ Private Practice, 1203 Geneva, Switzerland \\ Correspondence should be addressed to Luis Pestana, luis.pestana@bluewin.ch \\ Received 17 May 2011; Accepted 14 June 2011 \\ Academic Editors: J. Bruges Armas and C. G. Mackworth-Young
}

Copyright ( $) 2011$ Sonsoles Reneses et al. This is an open access article distributed under the Creative Commons Attribution License, which permits unrestricted use, distribution, and reproduction in any medium, provided the original work is properly cited.

\begin{abstract}
We assessed the contribution of four baseline markers-HLA-DRB1 shared epitope (SE), -308 tumor necrosis factor $\alpha$ gene promoter polymorphism, rheumatoid factor, and anticitrullinated peptide antibodies—-for predicting persistent activity (DAS28 score $\geq 2.6$ ) after one year of followup in a cohort of 201 patients with recent-onset rheumatoid arthritis (RA) or undifferentiated arthritis (UA) aged 16 years or older who had a 4-week to 12 -month history of swelling of at least two joints. Patients had not been previously treated with corticosteroids or disease-modifying antirheumatic drugs (DMARD). In the best logistic regression model, only two variables were retained: SE positivity and number of DMARD administered (area under the curve $=76.4 \% ; 95 \%$ CI: $69.2 \%, 84.4 \% ; P<0.001$ ). The best linear regression model also included these two variables, explaining only $22.5 \%$ of the variability of DAS28 score. In this study, given an equal number of DMARD administered, the probability of persistent activity in patients with recent-onset RA or UA was significantly influenced by SE presence.
\end{abstract}

\section{Introduction}

The high variability of disease activity among patients newly presenting with rheumatoid arthritis (RA) or undifferentiated arthritis (UA) makes it necessary to know which patients will develop persistent disease, regardless of diagnosis, so that they can be treated more aggressively from the outset and to avoid inappropriate treatment of patients more prone to remission.

Several methodological issues must be considered when studying predictors of persistent activity in patients with recent-onset RA. First, when the disease is in its early stages, patients seldom fulfill the 1987 American Rheumatism Association (ARA) revised criteria for RA [1]. Patients who do not fulfill criteria for definite RA at first presentation might be classified as having definite RA at a subsequent time point, but many cases remain unclassifiable (UA) [25]. There is an important proportion of newly presenting patients who do not satisfy these criteria, but for whom there is a compelling reason to treat with disease-modifying antirheumatic drugs (DMARD), or who on followup develop persistent disease even if there is no change in their classification status. Recently, new classification criteria for RA have been developed in an attempt to increase sensitivity in recent-onset cases [6]. Whether the fulfillment of ARA criteria is useful to predict activity is unknown [7].

Second, since treatments are not randomly assigned in nonexperimental studies, disease activity may be influenced by the type of treatment patients receive. Patients with more severe disease are more likely to be treated more aggressively. This confounding effect can be controlled for by using multivariate regression models [8]. 
Third, factors selected by different authors as potentially predictive of a poor outcome are very heterogeneous and highly variable. The combined role of genetic and immunologic factors in the development of severe RA has been the subject of recent investigations. Recent data support the hypothesis that the presence of HLA DRB1 shared epitope (SE) alleles can trigger immune reactions such as the production of anticyclic citrullinated peptide antibodies (anti-CCP) [9]. RA patients showing these antibodies in the early stages of the disease could develop more severe disease than those who lack them [10]. RF positivity seems to be related to active disease, but no definite conclusions have been reached regarding its value as a predictor of disease activity in RA [11]. Tumor necrosis factor alpha (TNF $\alpha)$ plays a pivotal role in regulating the inflammatory response in RA. However, there are few reports on the role of the G-toA polymorphism at position 308 of the TNF $\alpha$ gene promoter $(-308 \mathrm{TNF} \alpha)$ as an independent marker of disease activity in recent-onset RA $[12,13]$; no association has been seen in RF-positive patients in particular [14]. Additional cohort studies including $-308 \mathrm{TNF} \alpha$ among the predictor variables are needed. Although -308 TNF $\alpha$ [12-14], SE alleles, [1522] RF, [23-29], and anti-CCP [30-38] have all been studied as potential predictors for persistent activity in cohort studies of recent-onset RA, so far no study has investigated the combined effect of this particular set of factors. The combination of several markers could increase the capacity to predict persistent disease in patients with recent-onset RA [39] and the identification of markers associated with a poor outcome would facilitate the development of new drug targets [40].

Finally, since there is no consensus definition of disease activity in recent-onset RA, the use of different definitions may generate substantial variation among studies [41]. As no "gold standard" exists, a disease activity score based on a reduced joint count (DAS28), [42] or other disease activity indexes [43] can be used. A DAS28 $\geq 2.6$ is considered indicative of active disease, while a DAS2 $8<2.6$ corresponds to fulfillment of the preliminary ARA criteria for clinical remission in RA [44].

In this study, multivariate logistic and lineal regression was used to find a model based in immunogenetic markers that predicts persistent activity in patients with recent-onset RA or UA. The study is based in a recent-onset inflammatory polyarthritis (IP) register established in Seville, Spain, in January 2002 to look into various diagnostic, prognostic and therapeutic issues [45-47].

\section{Materials and Methods}

We studied a prospective cohort of 201 consecutive patients with recent-onset RA or UA (disease duration $\leq 1$ year) who were referred to our recent-onset IP unit from January 2002 through December 2006. Patients were referred from primary health care centers, emergency services, and outpatient rheumatology clinics of the Virgen del Rocío University Hospital Health District in Seville, Spain (population 774619 according to the 2002 census). Details of the caseascertainment and follow-up procedure have been previously described [45].
2.1. Subjects. To be included in the recent-onset IP register, patients referred to the unit had to reside in the hospital health district catchment area, be at least 16 years old, and have at least two swollen joints lasting for a minimum of 4 weeks and a maximum of 12 months.

The 1987 ARA criteria for RA [1] and international classification criteria for other rheumatic diseases [48] were used at baseline and in all follow-up assessments and cumulatively applied. Patients were classified as having RA if they fulfilled at least four of the seven 1987 ARA criteria for RA; those who did not fulfill at least four of these seven criteria and did not fulfill the classification or diagnostic criteria of any other particular rheumatic disease were classified as having UA. Cases classified as RA during any visit (at $0,1,3,6$, 9, and 12 months) and cases still classified as having UA at the end of followup were included in this study; patients with alternative diagnoses were excluded. Even if the new ACR/EULAR classification criteria for RA have been published after our statistical analysis was completed, we have calculated the proportion of patients who fulfill them for informative purposes [6].

From January 2002 through December 2006, 998 patients were referred to the recent-onset IP unit. Of such patients, $469(47.0 \%)$ fulfilled the criteria for inclusion in the register, but $33(7.0 \%)$ were lost to follow-up. This left a total of 436 registered patients, of whom 201 (46.1\%) had completed the first year of followup by the time of this analysis. All patients were of Spanish descent. At baseline, no patient had previously received corticosteroids or DMARD. Blood samples for laboratory tests were collected and frozen before treatment was begun.

2.2. Genetic Markers. DNA from peripheral blood was obtained using standard methods. HLA-DRB1 SE alleles were genotyped using a reverse dot-blot kit with sequencespecific oligonucleotide probes (Dynal Reli SSO HLA-DRB1 typing kits; Dynal Biotech, Bromborough, UK). When necessary, high-resolution typing of HLA-DRB $1 * 01, \mathrm{DRB} 1 * 04$ and DRB1*14 samples was performed using Dynal Allset SSP DRB $1 * 01, \mathrm{DRB} 1 * 04$ and $\mathrm{DRB} 1 * 14$, respectively. The frequency of SE in a healthy control group from our district catchment area was 30\% (28\% heterozygous and 2\% homozygous for the SE allele).

Samples were genotyped for -308 TNF $\alpha$ using a TaqMan 5' allelic discrimination assay (Custom TaqMan SNP Genotyping Assays method, Applied Biosystems, Foster City, Calif, USA). Allele-specific probes were labeled with VIC and FAM fluorescent dyes. Polymerase chain reaction (PCR) was carried out in a total reaction volume of $8 \mu \mathrm{L}$ with the following amplification protocol: denaturation at $95^{\circ} \mathrm{C}$ for $10 \mathrm{~min}, 40$ cycles of denaturation at $93^{\circ} \mathrm{C}$ for $15 \mathrm{sec}$ and annealing and extension at $60^{\circ} \mathrm{C}$ for $1 \mathrm{~min}$. After PCR, the genotype of each sample was automatically attributed using the SDS 1.3 software for allelic discrimination. The frequencies of $-308 \mathrm{TNF} \alpha$ genotypes in a healthy control group from our district catchment area were $80 \%$ for GG, $17 \%$ for GA and 3\% for AA. 
2.3. Immunologic Markers. Anti-CCP antibodies were tested by second-generation ELISA (QUANTA Lite CCP IgG ELISA. INOVA Diagnostic Inc., San Diego, Calif, USA; positive: $>20 \mathrm{IU} / \mathrm{mL}$ ), and RF by nephelometry on a BN II instrument (Dade Behring, Marburg, Germany) using the $\mathrm{N}$ Latex RF method (Dade Behring) [46, 47]; levels > $50 \mathrm{IU} / \mathrm{mL}$ were considered positive using the optimal cutoff value reported by other authors [49]. In a healthy control group from our district catchment area, the RF level at percentile 95 was $15 \mathrm{IU} / \mathrm{mL}$, and the highest anti-CCP level was $10 \mathrm{UI} / \mathrm{mL}$.

2.4. Treatments. Treatment with corticosteroids and DMARD (methotrexate, sulphasalazine, chloroquine, leflunomide, cyclosporine, azathioprine, or combinations thereof) during the entire followup period was assessed.

2.5. Disease Activity Measurements. DAS28 (range 0-10) was recorded for all patients after 12 months. A DAS $28<2.6$ was considered indicative of no disease activity or remission, and a DAS28 $\geq 2.6$ was considered indicative of active disease [44].

2.6. Statistical Methods. The dependent variable was the DAS28 obtained at 12 months. The independent variables were the SE status, anti-CCP and RF (either status or levels), and $-308 \mathrm{TNF} \alpha$ genotype (GG or GA/AA; as there were few GA and AA cases, these two categories were collapsed) obtained at baseline. As the probability of persistent activity may be influenced by the treatment the patients received, this confounding factor was entered as an additional independent variable. The treatment given throughout the 12 months of followup was corticosteroids, categorized dichotomously (yes/no), and/or DMARD, categorized either dichotomously (yes/no) or as the number of drugs given (from 0 to 3 ). Multinomial regression models were also used to adjust the possible differences between disease classification (RA or UA) throughout followup.

All data were recorded in an Access 2000 database and then exported to the Statistical Package for the Social Sciences (SPSS) v. 15.0 for statistical analysis.

For an alpha level of 0.05 , an anticipated "medium" effect size of 0.15 (according to Cohen's convention for multiple regression) and an assumed 10\% rate of attrition, the minimum sample size required to reach a statistical power of 0.80 in a multiple regression model with eight predictor variables would be 108 .

We calculated absolute frequencies and percentages for qualitative variables, and means and standard deviations for quantitative variables. Variables that are predictive for disease activity at one year were identified by univariate and multivariate logistic and linear regression models. For univariate analyses we used Student's $t$-test, $\chi^{2}$ or Fisher's exact test, as appropriate. Normality and homoscedasticity contrasts (Kolmogorov-Smirnov and Levene tests, resp.) were undertaken for parametric tests. For multivariate analysis, Wald's statistic (logistic regression) or Student's $t$ test (linear regression) were used for stepwise exclusion of variables weakly associated with the dependent variable, as indicated by a $P$ value $\geq 0.15$. Since the $\mathrm{SE}$ variable is polytomic, it was analyzed by creating a dummy variable with the first category $(-/-)$ used as the reference. Full and reduced models were compared with the G statistic (logistic regression) or partial multiple $F$-test (linear regression). The linearity of continuous variables was checked by the Box-Tidwell test. Potential interactions among the variables in the model were studied. Variables with a $P$ value > 0.05 were analyzed as potential confounders, and they were considered as such whenever their coefficients changed by $>20 \%$. Multicollinearity among independent variables was assessed by the variance inflation factor, independence by the Durbin-Watson test, normality by the Shapiro-Wilk test, and homoscedasticity of the residues by the dispersion diagram among residues and the estimated values. Outliers were identified by means of Cook's distance. In the logistic regression, goodness of fit was assessed with the Hosmer-Lemeshow goodness-of-fit analysis, and discrimination was reported as the area under the receiver operating characteristic (ROC) curve. In the linear analysis, goodness of fit was assessed with the corrected determination coefficient $\left(R^{2}\right)$. All contrasts were two-tailed, and the significance level was set at $<0.05$.

\section{Results}

The characteristics of the study population are shown in Table 1. The $-308 \mathrm{TNF} \alpha$ could not be genotyped in 7 patients. Of the remaining 194 patients, 39 (20.1\%) had GA or AA genotypes. Sixty-nine patients $(34.3 \%)$ were heterozygous $(-/+)$, and $16(8.0 \%)$ were homozygous $(+/+)$ for the SE allele; $85(42.3 \%)$ were RF-positive, and 88 $(43.8 \%)$ were anti-CCP-positive. The number of patients fulfilling $\geq 4$ ARA criteria for RA increased from 108 (53.7\%) at baseline to $142(70.6 \%)$ after 1 year (i.e., 34 of the 93 patients having UA at baseline fulfilled $\geq 4$ ARA criteria for RA after 1 year). The number of patients fulfilling the new ACR/EULAR classification criteria for RA [6] increased from $145(72.1 \%)$ at baseline to $154(76.6 \%)$ after 1 year. Sometime between the baseline visit and the end of the follow-up period, 190 patients $(94.5 \%)$ were treated with DMARD and 185 (92.0\%) received corticosteroids. All patients were treated with corticosteroids and/or DMARD during the follow-up period. Mean (SD) values for DAS28 were 6.3 (1.4) at study entry and 3.5 (1.3) at 1 year.

In univariate analyses, qualitative variables significantly associated with a DAS $28 \geq 2.6$ at one year were positive SE $(P<0.001)$, fulfillment of the 1987 ARA criteria $(P=0.002)$, and treatment with DMARD $(P=0.003)$. As for quantitative variables, only anti-CCP levels $(P=0.030)$ and the number of DMARD $(P<0.001)$ were significantly associated with a DAS28 $\geq 2.6$ (Table 2).

Table 3 shows the results of univariate and multivariate logistic regression for DAS28 at one year. In univariate regression analyses, only positive SE $(P<0.001)$ and the number of DMARD given during followup $(P<0.001)$ were associated with a DAS28 $\geq 2.6$. Multivariate logistic regression analysis resulted in a model in which a DAS28 $\geq$ 2.6 at one year of followup was significantly predicted by the presence of SE (OR: 4.72 [95\% CI: 2.17, 10.25]; $P<0.001$ ) and the number of DMARD (OR: 2.54 [95\% CI: 1.64, 3.95]; 
TABLE 1: Characteristics of patients $(N=201)$.

\begin{tabular}{|c|c|c|}
\hline Variables $^{\mathrm{a}}$ & $n(\%)$ & Mean (SD) \\
\hline Age (years) & - & $51.4(17.2)$ \\
\hline Women & $144(71.6)$ & - \\
\hline Positive anti-CCP & $88(43.8)$ & $68.3(97.8)$ \\
\hline Positive RF & $85(42.3)$ & $137.0(281.5)$ \\
\hline \multicolumn{3}{|l|}{ SE } \\
\hline$-1-$ & $116(57.7)$ & - \\
\hline$-1+$ & $69(34.3)$ & - \\
\hline$+/+$ & $16(8.0)$ & - \\
\hline \multicolumn{3}{|l|}{$-308 \mathrm{TNF} \alpha^{\mathrm{b}}$} \\
\hline GG & $155(79.9)$ & - \\
\hline GA/AA & $39(20.1)$ & - \\
\hline CRP (mg/L) & - & $13.8(15.7)$ \\
\hline $\operatorname{ESR}(\mathrm{mm} / \mathrm{h})$ & - & $37.5(22.0)$ \\
\hline Swollen joint count & - & $12.0(6.9)$ \\
\hline Tender joint count & - & $14.1(7.6)$ \\
\hline DAS28 & - & $6.3(1.4)$ \\
\hline HAQ & - & $1.1(0.7)$ \\
\hline \multicolumn{3}{|l|}{ Classification criteria } \\
\hline 1987 ARA criteria for RA & $108(53.7)$ & - \\
\hline UA & $93(46.3)$ & - \\
\hline \multicolumn{3}{|l|}{ Number of DMARD } \\
\hline 0 & $11(5.5)$ & - \\
\hline 1 & $24(11.9)$ & - \\
\hline 2 & $88(43.8)$ & - \\
\hline 3 & $78(38.8)$ & - \\
\hline \multicolumn{3}{|l|}{ DMARD } \\
\hline Methotrexate (MTX) & $162(80.6)$ & - \\
\hline Leflunomide (LEF) & $81(40.3)$ & - \\
\hline Chloroquine (CLQ) & $69(34.3)$ & - \\
\hline Sulphasalazine (SLZ) & $54(26.9)$ & - \\
\hline Cyclosporine (CYC) & $16(8.0)$ & - \\
\hline Azathioprine & $3(1.5)$ & - \\
\hline MTX + SLZ + CLQ & $74(36.8)$ & - \\
\hline MTX + LEF & $59(29.4)$ & - \\
\hline MTX + SLZ & $39(19.4)$ & - \\
\hline MTX + CYC & $16(8.0)$ & - \\
\hline MTX + CLQ & $31(15.4)$ & \\
\hline \multicolumn{3}{|l|}{ Corticosteroids } \\
\hline Yes & $185(92.0)$ & - \\
\hline No & $16(8.0)$ & - \\
\hline
\end{tabular}

${ }^{a}$ All variables measured at baseline, except treatments, which are accumulated throughout followup.

$\mathrm{b}-308 \mathrm{TNF} \alpha$ could not be genotyped in 7 patients.

Abbreviations: SD: standard deviation. Anti-CCP: anti-cyclic citrullinated peptide antibodies. RF: rheumatoid factor. SE: shared epitope. $-308 \mathrm{TNF} \alpha$ : G-to-A polymorphism at position 308 of the TNF $\alpha$ gene promoter. CRP: C-reactive protein. ESR: erythrocyte sedimentation rate. DAS28: Disease Activity Score. HAQ: Health Assessment Questionnaire. ARA: American Rheumatism Association. RA: rheumatoid arthritis. UA: undifferentiated arthritis. DMARD: disease-modifying antirheumatic drugs.
$P<0.001)$, but not by any other variable. That means that for any two patients administered the same number of DMARD, the probability of persistent activity at 1 year is almost 5 times greater in a patient with SE than in a patient without SE. For a cutoff value of 0.05 , the model had a sensitivity of $81.9 \%$ and a specificity of $56.1 \%$, with an AUC of $76.4 \%$ (95\% CI: $68.9 \%, 83.8 \%)$, that is, significantly higher than $50 \%(P<0.001)$, indicating that the model showed fair discriminatory power. The model had also fair accuracy (i.e., it correctly predicted $74.6 \%$ of the cases).

Table 4 shows the results of univariate and multivariate linear regression for DAS28 at one year. In univariate regression analyses, anti-CCP status $(P=0.003), \mathrm{RF}$ status $(P=0.004)$, SE heterozygosity $(P<0.001)$, SE homozygosity $(P=0.017)$ and the number of DMARD $(P<0.001)$ were associated with higher DAS28 at one year. In the linear regression analysis, a higher DAS28 was significantly predicted by SE heterozygosity ( $\beta$ coefficient: 0.67 [95\% CI: $0.32,1.01] ; P<0.001$ ), SE homozygosity ( $\beta$ coefficient: 0.73 [95\% CI: $0.11,1.35] ; P=0.021$ ) and the number of DMARD ( $\beta$ coefficient: 0.63 [95\% CI: 0.43, 0.82]; $P<0.001$ ), but not by any other variable (partial $F$ tests $=0.115 ; P=0.995 ; d f=$ 6.195). That means that for any two patients administered the same number of DMARD, the DAS28 score at 1 year will be 0.73 points greater in a patient homozygous for SE than in a patient without SE. This model explained only $22.5 \%$ of the variability of the dependent variable $\left(R^{2}=0.225\right)$.

In these models, no significant interactions among variables were noted, and no variable was a confounder. All criteria for the use of multivariate linear regression were fulfilled: independence, normality and linearity of the independent variables, absence of multicollinearity among them, and homoscedasticity of the residues. No patient showed a Cook's distance $>1$.

\section{Discussion}

Several cohort studies of populations similar to ours have investigated the value of different combinations of variables, including HLA-DRB1 SE alleles, $-308 \mathrm{TNF} \alpha$, RF, and antiCCP for predicting disease activity among patients with recent-onset RA [12-37]. These studies differed methodologically in terms of referral and recruitment procedures, inclusion criteria, disease duration, variables assessed at presentation, followup until assessment of outcome, and disease activity scoring methods. Our study is the first to investigate this particular set of four immunogenetic markers using multivariate regression. Moreover, the potentially confounding effects of the classification criteria (RA versus UA) and the type of treatment given were controlled for by including these variables in the regression analyses.

Some studies have found a significant association between SE alleles and disease activity in recent-onset RA $[15,17,19]$, and some have not. $[16,18,20-22]$ Several have not used multivariate statistical methods $[15,17,21]$. Our results show that persistent activity at one year, assessed with the DAS28, is significantly influenced by the presence of SE in patients with recent-onset RA or UA. This finding is consistent across univariate and multivariate logistic and 
TABLE 2: Univariate analyses to identify predictors of a disease activity score (DAS28) $\geq 2.6$ at one year.

\begin{tabular}{|c|c|c|c|}
\hline Variables $^{\mathrm{a}}$ & DAS2 $8<2.6 N=57^{b}$ & DAS2 $282.6 N=144^{\mathrm{b}}$ & $P$ value \\
\hline \multicolumn{4}{|l|}{ Anti-CCP: $n(\%)$} \\
\hline Positive & $19(33.3)$ & $69(47.9)$ & \multirow[t]{2}{*}{0.060} \\
\hline Negative & $38(66.7)$ & $75(52.1)$ & \\
\hline Anti-CCP: mean (SD) & $46.7(81.2)$ & $76.9(102.7)$ & 0.030 \\
\hline \multicolumn{4}{|l|}{ RF: $n(\%)$} \\
\hline Positive & $22(38.6)$ & $63(43.7)$ & \multirow[t]{2}{*}{0.167} \\
\hline Negative & $35(61.4))$ & $81(56.3)$ & \\
\hline RF: mean (SD) & $127.3(233.8)$ & $140.8(298.9)$ & 0.759 \\
\hline \multicolumn{4}{|l|}{ SE: $n(\%)$} \\
\hline$-1-$ & $46(80.7)$ & $70(48.6)$ & \multirow[t]{3}{*}{$<0.001$} \\
\hline$-/+$ & $8(14.0)$ & $61(42.4)$ & \\
\hline$+/+$ & $3(5.3)$ & $13(9.0)$ & \\
\hline \multicolumn{4}{|l|}{$-308 \mathrm{TNF} \alpha: n(\%)$} \\
\hline GG & $42(76.4)$ & $113(81.3)$ & \multirow[t]{2}{*}{0.443} \\
\hline GA/AA & $13(23.6)$ & $26(18.7)$ & \\
\hline \multicolumn{4}{|l|}{ Classification criteria } \\
\hline 1987 ARA criteria for RA & $31(54.4)$ & $111(77.1)$ & \multirow[t]{2}{*}{0.002} \\
\hline UA & $26(45.6)$ & $33(22.9)$ & \\
\hline \multicolumn{4}{|l|}{ DMARD: $n(\%)$} \\
\hline Yes & $45(78.9)$ & $136(94.4)$ & \multirow[t]{2}{*}{0.003} \\
\hline No & $12(21.1)$ & $8(5.6)$ & \\
\hline Number of DMARD: mean (SD) & $1.16(0.774)$ & $1.74(0.826)$ & $<0.001$ \\
\hline \multicolumn{4}{|l|}{ Corticosteroids: $n(\%)$} \\
\hline Yes & $53(93.0)$ & $132(91.7)$ & \multirow[t]{2}{*}{0.756} \\
\hline No & $4(7.0)$ & $12(8.3)$ & \\
\hline
\end{tabular}

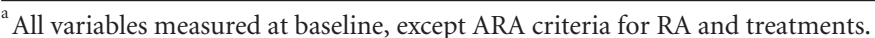

${ }^{b}$ Except for -308 TNF $\alpha$, where 7 cases ( 2 with DAS28 $<2.6$, and 5 with DAS28 $\geq 2.6$ ) could not be genotyped.

Abbreviations: Anti-CCP: anticyclic citrullinated peptide antibodies. SD: standard deviation. RF: rheumatoid factor. SE: shared epitope. -308 TNF $\alpha$ : G-to-A polymorphism at position 308 of the TNF $\alpha$ gene promoter. ARA: American Rheumatism Association. RA: rheumatoid arthritis. UA: undifferentiated arthritis. DMARD: disease-modifying antirheumatic drugs.

TABLE 3: Univariate and multivariate logistic analyses to identify predictors of a disease activity score (DAS28) $\geq 2.6$ (yes/no) at one year.

\begin{tabular}{|c|c|c|c|c|}
\hline Variables $^{\mathrm{a}}$ & Univariate OR (95\% CI) & $P$ value & Multivariate OR $(95 \% \mathrm{CI})^{\mathrm{b}}$ & $P$ value $^{\mathrm{b}}$ \\
\hline Anti-CCP (neg. versus pos.) & $1.84(0.97,3.49)$ & 0.062 & - & - \\
\hline RF (neg. versus pos.) & $1.59(0.82,3.06)$ & 0.169 & - & - \\
\hline $\operatorname{SE}(-/-$ versus $-/+$ or $+/+)$ & $4.42(2.12,9.22)$ & $<0.001$ & $4.72(2.17,10.25)$ & $<0.001$ \\
\hline$-308 \mathrm{TNF} \alpha(\mathrm{GA} / \mathrm{AA}$ versus GG) & $1.34(0.63,2.84)$ & 0.444 & - & - \\
\hline Classification criteria (UA versus. RA) & $1.79(0.66,4.82)$ & 0.249 & - & - \\
\hline Number of DMARD & $2.44(1.61,3.70)$ & $<0.001$ & $2.54(1.64,3.95)$ & $<0.001$ \\
\hline Corticosteroids (no versus yes) & $0.83(0.26,1.02)$ & 0.756 & - & - \\
\hline \multicolumn{5}{|c|}{ DAS28 $\geq 2.6: 71.60 \%$ (95\% CI: $69.87 \%, 73.33 \%)$} \\
\hline \multicolumn{5}{|c|}{$G$-test for full versus. reduced models: $G=2.876 ; \mathrm{df}=4 ; P=\mathrm{NS}$. } \\
\hline \multicolumn{5}{|c|}{$G$-test for logistic model: $G=38.243 ; d f=2 ; P<0.001$} \\
\hline \multicolumn{5}{|c|}{ Hosmer-Lemeshow: $C=7.124 ; \mathrm{df}=6 ; P=0.310$} \\
\hline
\end{tabular}

${ }^{a}$ All variables measured at baseline, except classification criteria and treatments.

${ }^{b}$ Values not shown for variables not retained in the model, that is, those with $P$ values $\geq 0.15$.

Abbreviations: OR: odds ratio. CI: confidence interval. Anti-CCP: anticyclic citrullinated peptide antibodies. RF: rheumatoid factor. SE: shared epitope. -308 TNF $\alpha$ : G-to-A polymorphism at position 308 of the TNF $\alpha$ gene promoter. UA: undifferentiated arthritis. RA: rheumatoid arthritis. DMARD: diseasemodifying antirheumatic drugs. 
TABLE 4: Univariate and multivariate linear analyses to identify predictors for disease activity score (DAS28) at one year.

\begin{tabular}{|c|c|c|c|c|}
\hline Variables $^{\mathrm{a}}$ & $\begin{array}{c}\text { Univariate } \beta \text { coeff. (95\% } \\
\text { CI) }\end{array}$ & $P$ value (Student's $t$ ) & $\begin{array}{c}\text { Multivariate } \beta \text { coeff. (95\% } \\
\text { CI) }\end{array}$ & $P$ value (Student's $t)^{\mathrm{b}}$ \\
\hline $\begin{array}{l}\text { Anti-CCP (neg. versus } \\
\text { pos.) }\end{array}$ & $0.57(0.20,0.93)$ & 0.003 & - & - \\
\hline RF (neg. versus pos.) & $0.56(0.18,0.93)$ & 0.004 & - & - \\
\hline $\operatorname{SE}(-/-$ versus $-/+)$ & $0.74(0.36,1.03)$ & $<0.001$ & $0.67(0.32,1.01)$ & $<0.001$ \\
\hline $\operatorname{SE}(-/-$ versus $+/+)$ & $0.83(0.15,1.51)$ & 0.017 & $0.73(0.11,1.35)$ & 0.021 \\
\hline $\begin{array}{l}-308 \mathrm{TNF} \alpha(\mathrm{GA} / \mathrm{AA} \\
\text { versus } \mathrm{GG})\end{array}$ & $0.01(-0.46,0.86)$ & 0.980 & - & - \\
\hline $\begin{array}{l}\text { Classification criteria (UA } \\
\text { versus RA) }\end{array}$ & $-0.29(-0.31,0.89)$ & 0.342 & - & - \\
\hline Number of DMARD & $0.66(0.46,0.86)$ & $<0.001$ & $0.63(0.43,0.82)$ & $<0.001$ \\
\hline $\begin{array}{l}\text { Corticosteroids (yes } \\
\text { versus. no) }\end{array}$ & $-0.56(-1.24,0.15)$ & 0.125 & - & - \\
\hline
\end{tabular}

$$
\begin{gathered}
\text { DAS28 at } 1 \text { year }=2.24+0.67 \mathrm{SE}(-/+)+0.73 \mathrm{SE}(+/+)+0.63 \text { number of DMARDs } \\
\qquad R^{2}=0.225 ; F=20.373 ; P<0.001 .
\end{gathered}
$$

\footnotetext{
all variables measured at baseline, except classification criteria and treatments.

b Values not shown for variables not included in the model, that is, those with $P$ values $\geq 0.15$.

Abbreviations: CI: confidence interval. Anti-CCP: anticyclic citrullinated peptide antibodies. RF: rheumatoid factor. SE: shared epitope. -308 TNF $\alpha$ : Gto-A polymorphism at position 308 of the TNF $\alpha$ gene promoter. UA: undifferentiated arthritis. RA: rheumatoid arthritis. DMARD: disease-modifying antirheumatic drugs.
}

linear analyses (Tables 2, 3, and 4). However, since RA is a multigenic inflammatory disorder, it is likely that other factors are involved in its outcome. The possibility that the $-308 \mathrm{TNF} \alpha$ may have prognostic implications is currently being debated. In a seropositive RA inception cohort, no statistically significant differences were seen in DAS between patients with GA or AA genotypes and those with the GG genotype [14]. Other studies that, like ours, were not confined to seropositive RA patients have also suggested that the $-308 \mathrm{TNF} \alpha$ is not a genetic marker for disease activity in recent-onset RA $[12,13]$. In this study, the GA/AA genotypes were not retained in any model, either logistic or linear, and not even in the univariate analyses (Tables 2,3 , and 4).

Of the 201 patients analyzed, only $42.3 \%$ were positive for RF. This low percentage resembles the values found in other studies. $[9,18,28]$ Besides the fact that our patients had recent-onset RA or UA rather than long-term RA, another possible explanation for the low frequency of RF positivity may be that, as recommended by some to predict outcome, [49] we used high cutoff values for RF ( $>50 \mathrm{IU} / \mathrm{mL}$, instead of $>40 \mathrm{IU} / \mathrm{mL},>20 \mathrm{IU} / \mathrm{mL}$, or even $>10 \mathrm{IU} / \mathrm{mL}$ in other studies). Had we used a cutoff value of $\geq 40 \mathrm{IU} / \mathrm{mL}$, the frequency of RF positivity would have been $58.7 \%$, instead of $42.3 \%$. Several studies have reported that RF is a good predictor of disease activity [23, 24, 26-31]. However, in our univariate analyses RF, treated either as a qualitative or a quantitative variable, was not significantly associated with DAS28 (Table 2). Additionally, in the multivariate analyses, RF was not a prognostic factor for disease activity (Tables 3 and 4). Similar results have been found in other cohorts of recent-onset RA patients, both in Spain [22] and elsewhere $[21,25,30,32]$.
In this community-based cohort, only $88(43.8 \%)$ of the 201 patients with recent-onset RA or UA were positive for anti-CCP at baseline. A low frequency of positivity at presentation has been recorded in other recent-onset RA cohorts [30, 32, 34-36], and it may be indicative of earlystage disease. The usefulness of anti-CCP for predicting disease activity in patients with recent-onset RA has been evaluated in several cohort studies. Some have suggested it is a marker for active disease, as measured with either the SJC $[30,33-36,38]$ or the DAS28, $[21,30,36]$, but others have not confirmed an association. [22, 31, 32, 37] Only a few of these studies have used multivariate statistical methods [22, 30, 32, 38]. Predictive value may depend on whether anti-CCP status or titers are considered. In our univariate analyses, patients who were positive for anti-CCP at presentation had not more disease activity at 1 year than patients who were negative (Table 2 ). When quantitative values were used, anti-CCP antibodies were significantly associated with DAS28 (Table 2). However, this marker was not a predictor of this outcome in regression models (Tables 3 and 4). Similar results have been found in other studies in which multivariate analyses have been performed [22, 32, 38].

The number of patients who fulfilled $\geq 4$ ARA criteria for RA increased with length of followup. Thus, it is advisable to use a cumulative approach to the classification of disease. In the community-based Norfolk Arthritis Register (NOAR), the percentage of patients classified as having RA using the above criteria increased from $38 \%$ at baseline to $66 \%$ at 5 years. [7] In our cohort of 463 patients with recent-onset IP, $108(23.3 \%)$ fulfilled $\geq 4$ ARA criteria for RA when first seen, and $142(30.7 \%)$ at 1 year. The number of patients fulfilling the new RA classification criteria [6] increased from 
$145(72.1 \%)$ at baseline to $154(76.6 \%)$ after 1 year. The 1987 ARA classification criteria for RA, derived from patients with long-standing established RA, were not designed to identify patients with recent-onset disease, and the current management of RA is intended to prevent patients reaching a stage when they satisfy these criteria. In this cohort, we included patients fulfilling $\geq 4$ of the 7 ARA criteria for RA and UA patients, since, regardless of diagnosis, DMARD therapy was used as an indicator of the physician's opinion that the patient was at risk of developing persistent disease in $94.5 \%$ of patients. The value of these criteria to predict active disease in patients with recent-onset disease has been questioned [7]. In this cohort, the fulfillment of ARA criteria for RA was not predictive for disease activity at 1 year (Tables 3 and 4$)$.

In our study, based on routine care, the treatment given over the 12 months of followup was included in the univariate and multivariate analyses and was significantly and negatively related to disease activity in every analysis (Tables 2, 3, and 4). Since treatment was not a confounder in multivariate analyses and DMARD have limited efficacy, this could indicate that, at least in a subgroup of patients, persistent disease activity might be related not to insufficient treatment with DMARD but to a failure to respond to conventional DMARD. A post hoc analysis of data from the BeSt study has shown that patients who failed to respond to methotrexate were unlikely to respond to other conventional DMARD, [50] and a recent study from the community-based NOAR has identified SE positivity as the strongest predictor of methotrexate monotherapy inefficacy in patients with early inflammatory polyarthtitis [51]. The ability of DMARD to prevent radiological damage has also been questioned [52]. In a previous study we have found that erosive damage at 1 year in patients with recent-onset RA is significantly influenced by SE homozygosity and the presence of baseline erosions, but not by RF status, anti-CCP status, $-308 \mathrm{TNF} \alpha$ genotype or treatment with conventional DMARD [53].

In conclusion, for patients with recent-onset RA or UA treated with the same number of DMARD, the probability of persistent activity is significantly influenced by SE presence. Positive RF and anti-CCP at baseline, as well as the presence of the AA or GA genotypes of $-308 \mathrm{TNF} \alpha$ or the fulfillment of criteria for RA, as opposed to UA classification, were not good predictors of disease activity.

\section{Funding}

Immunogenetic tests were partially funded by grant FIS07/0061 from the Fondo de Investigaciones Sanitarias (Spain).

\section{Acknowledgments}

The authors thank Dr. M. L. Clark for improving the use of English in the paper and Pilar Font for advice in statistical analysis.

\section{References}

[1] F. C. Arnett, S. M. Edworthy, D. A. Bloch et al., "The American Rheumatism Association 1987 revised criteria for the classifi- cation of rheumatoid arthritis," Arthritis and Rheumatism, vol. 31, no. 3, pp. 315-324, 1988.

[2] K. Kaarela, M. J. Kauppi, and K. E. S. Lehtinen, "The value of the ACR 1987 criteria in very early rheumatoid arthritis," Scandinavian Journal of Rheumatology, vol. 24, no. 5, pp. 279281, 1995.

[3] B. J. Harrison, D. P. M. Symmons, E. M. Barrett, and A. J. Silman, "The performance of the 1987 ARA classification criteria for rheumatoid arthritis in a population based cohort of patients with early inflammatory polyarthritis," Journal of Rheumatology, vol. 25, no. 12, pp. 2324-2330, 1998.

[4] A. Saraux, J. M. Berthelot, G. Chalès et al., "Ability of the American College of Rheumatology 1987 criteria to predict rheumatoid arthritis in patients with early arthritis and classification of these patients two years later," Arthritis and Rheumatism, vol. 44, no. 11, pp. 2485-2491, 2001.

[5] H. R. Schumacher, "Early arthritis clinics. Much early arthritis is unclassified," Journal of Rheumatology, vol. 29, no. 11, pp. 2258-2260, 2002.

[6] D. Aletaha, T. Neogi, A. J. Silman et al., "2010 Rheumatoid arthritis classification criteria: an American College of Rheumatology/European League Against Rheumatism collaborative initiative," Arthritis and Rheumatism, vol. 62, no. 9, pp. 2569-2581, 2010.

[7] D. P. M. Symmons, J. M. W. Hazes, and A. J. Silman, "Cases of early inflammatory polyarthritis should not be classified as having rheumatoid arthritis," Journal of Rheumatology, vol. 30, no. 5, pp. 902-904, 2003.

[8] M. J. Glesby and D. R. Hoover, "Survivor treatment selection bias in observational studies: examples from the AIDS literature," Annals of Internal Medicine, vol. 124, no. 11, pp. 9991005, 1996.

[9] A. H. M. van der Helm-van Mil, K. N. Verpoort, F. C. Breedveld, T. W. J. Huizinga, R. E. M. Toes, and R. R. P. de Vries, "The HLA-DRB1 shared epitope alleles are primarily a risk factor for anti-cyclic citrullinated peptide antibodies and are not an independent risk factor for development of rheumatoid arthritis," Arthritis and Rheumatism, vol. 54, no. 4, pp. 1117-1121, 2006.

[10] A. S. Wiik, "The immune response to citrullinated proteins in patients with rheumatoid arthritis: genetic, clinical, technical, and epidemiological aspects," Clinical Reviews in Allergy and Immunology, vol. 32, no. 1, pp. 13-21, 2007.

[11] D. Wilson, "Just the berries: rheumatoid factors in patients with rheumatoid arthritis," Canadian Family Physician, vol. 52, pp. 180-186, 2006.

[12] A. G. Wilson, N. de Vries, L. B. A. van de Putte, and G. W. Duff, "A tumour necrosis factor $\alpha$ polymorphism is not associated with rheumatoid arthritis," Annals of the Rheumatic Diseases, vol. 54, no. 7, pp. 601-603, 1995.

[13] J. K. Lacki, R. Moser, I. Korczowska, S. Mackiewicz, and W. Muller, "TNF- $\alpha$ gene polymorphism does not affect the clinical and radiological outcome of rheumatoid arthritis," Rheumatology International, vol. 19, no. 4, pp. 137-140, 2000.

[14] D. Khanna, H. Wu, G. Park et al., "Association of tumor necrosis factor $\alpha$ polymorphism, but not the shared epitope, with increased radiographic progression in a seropositive rheumatoid arthritis inception cohort," Arthritis and Rheumatism, vol. 54, no. 4, pp. 1105-1116, 2006.

[15] D. van Zeben, J. M. W. Hazes, A. H. Zwinderman et al., "Association of HLA-DR4 with a more progressive disease course in patients with rheumatoid arthritis: results of a followup study," Arthritis and Rheumatism, vol. 34, no. 7, pp. 822-830, 1991. 
[16] M. E. Suarez-Alamazor, S. Tao, F. Moustarah, A. S. Russell, and W. Maksymowych, "HLA-DR1, DR4, and DRB1 disease related subtypes in rheumatoid arthritis. Association with susceptibility but not severity in a city wide community based study," Journal of Rheumatology, vol. 22, no. 11, pp. 2027-2033, 1995.

[17] C. H. M. van Jaarsveld, H. G. Otten, J. W. G. Jacobs, A. A. Kruize, H. L. M. Brus, and J. W. J. Bijlsma, "Association of HLA-DR with susceptibility to and clinical expression of rheumatoid arthritis: re-evaluation by means of genomic tissue typing," British Journal of Rheumatology, vol. 37, no. 4, pp. 411-416, 1998.

[18] B. Harrison, W. Thomson, D. Symmons et al., "The influence of HLA-DRB1 alleles and rheumatoid factor on disease outcome in an inception cohort of patients with early inflammatory arthritis," Arthritis and Rheumatism, vol. 42, no. 10, pp. 2174-2183, 1999.

[19] C. Seidl, U. Koch, T. Buhleier et al., "Association of (Q)R/KRAA positive HLA-DRB1 alleles with disease progression in early active and severe rheumatoid arthritis," Journal of Rheumatology, vol. 26, no. 4, pp. 773-776, 1999.

[20] L. Gossec, M. Dougados, P. Goupille et al., "Prognostic factors for remission in early rheumatoid arthritis: a multiparameter prospective study," Annals of the Rheumatic Diseases, vol. 63, no. 6, pp. 675-680, 2004.

[21] B. van der Cruyssen, A. M. M. Miltenburg, F. van den Bosch et al., "Decrease of disease activity under ineffective therapy in DMARD-naive patients with early rheumatoid arthritis: role of antibody profiles and carriage of the HLA shared epitope in predicting decrease of disease activity," Journal of Rheumatology, vol. 34, no. 10, pp. 1992-1996, 2007.

[22] I. Vázquez, E. Graell, J. Gratacós et al., "Prognostic markers of clinical remission in early rheumatoid arthritis after two years of DMARDs in a clinical setting," Clinical and Experimental Rheumatology, vol. 25, no. 2, pp. 231-238, 2007.

[23] K. B. Eberhardt, L. Truedsson, H. Pettersson et al., "Disease activity and joint damage progression in early rheumatoid arthritis: relation to IgG, IgA, and IgM rheumatoid factor," Annals of the Rheumatic Diseases, vol. 49, no. 11, pp. 906-909, 1990.

[24] D. van Zeben, J. M. W. Hazes, A. H. Zwinderman, A. Cats, E. A. M. van der Voort, and F. C. Breedveld, "Clinical significance of rheumatoid factors in early rheumatoid arthritis: results of a follow up study," Annals of the Rheumatic Diseases, vol. 51, no. 9, pp. 1029-1035, 1992.

[25] M. A. van Leeuwen, J. Westra, P. L. C. M. van Riel, P. C. Limburg, and M. H. van Rijswijk, "IgM, IgA, and IgG rheumatoid factors in early rheumatoid arthritis predictive of radiological progression?" Scandinavian Journal of Rheumatology, vol. 24, no. 3, pp. 146-153, 1995.

[26] D. A. Houssien, T. Jónsson, E. Davies, and D. L. Scott, "Rheumatoid factor isotypes, disease activity and the outcome of rheumatoid arthritis: comparative effects of different antigens," Scandinavian Journal of Rheumatology, vol. 27, no. 1, pp. 46-53, 1998.

[27] B. Combe, M. Dougados, P. Goupille et al., "Prognostic factors for radiographic damage in early rheumatoid arthritis: a multiparameter prospective study," Arthritis and Rheumatism, vol. 44, no. 8, pp. 1736-1743, 2001.

[28] K. W. Drossaers-Bakker, A. H. Zwinderman, T. P. M. Vliet Vlieland et al., "Long-term outcome in rheumatoid arthritis: a simple algorithm of baseline parameters can predict radiographic damage, disability, and disease course at 12-year followup," Arthritis Care and Research, vol. 47, no. 4, pp. 383390, 2002.

[29] E. Knijff-Dutmer, W. Drossaers-Bakker, A. Verhoeven et al., "Rheumatoid factor measured by fluoroimmunoassay: a responsive measure of rheumatoid arthritis disease activity that is associated with joint damage," Annals of the Rheumatic Diseases, vol. 61, no. 7, pp. 603-607, 2002.

[30] A. Kastbom, G. Strandberg, A. Lindroos, and T. Skogh, "Anti$\mathrm{CCP}$ antibody test predicts the disease course during 3 years in early rheumatoid arthritis (the Swedish TIRA project)," Annals of the Rheumatic Diseases, vol. 63, no. 9, pp. 1085-1089, 2004.

[31] E. Berglin, T. Johansson, U. Sundin et al., "Radiological outcome in rheumatoid arthritis is predicted by presence of antibodies against cyclic citrullinated peptide before and at disease onset, and by IgA-RF at disease onset," Annals of the Rheumatic Diseases, vol. 65, no. 4, pp. 453-458, 2006.

[32] K. Forslind, I. Hafström, M. Ahlmén, B. Svensson, and BARFOT Study Group, "Sex: a major predictor of remission in early rheumatoid arthritis?" Annals of the Rheumatic Diseases, vol. 66, pp. 46-52, 2007.

[33] M. K. Söderlin, A. Kastbom, H. Kautiainen, M. LeirisaloRepo, G. Strandberg, and T. Skogh, "Antibodies against cyclic citrullinated peptide (CCP) and levels of cartilage oligomeric matrix protein (COMP) in very early arthritis: relation to diagnosis and disease activity," Scandinavian Journal of Rheumatology, vol. 33, no. 3, pp. 185-188, 2004.

[34] A. H. van der Helm-van Mil, K. N. Verpoort, F. C. Breedveld, R. E. Toes, and T. W. Huizinga, "Antibodies to citrullinated proteins and differences in clinical progression of rheumatoid arthritis," Arthritis research \& therapy., vol. 7, no. 5, pp. R949958, 2005.

[35] J. Rönnelid, M. C. Wick, J. Lampa et al., "Longitudinal analysis of citrullinated protein/peptide antibodies (anti-CP) during 5 year follow up in early rheumatoid arthritis: anti-CP status predicts worse disease activity and greater radiological progression," Annals of the Rheumatic Diseases, vol. 64, no. 12, pp. 1744-1749, 2005.

[36] N. G. Papadopoulos, G. Z. Tsiaousis, A. Pavlitou-Tsiontsi, A. Giannakou, and V. K. Galanopoulou, "Does the presence of anti-CCP autoantibodies and their serum levels influence the severity and activity in rheumatoid arthritis patients?" Clinical Reviews in Allergy and Immunology, vol. 34, no. 1, pp. 11-15, 2008.

[37] L. Innala, H. Kokkonen, C. Eriksson, E. Jidell, E. Berglin, and S. Rantapää-Dahlqvist, "Antibodies against mutated citrullinated vimentin are a better predictor of disease activity at 24 months in early rheumatoid arthritis than antibodies against cyclic citrullinated peptides," Journal of Rheumatology, vol. 35, no. 6, pp. 1002-1008, 2008.

[38] Y. El Miedany, S. Youssef, A. N. Mehanna, and M. El Gaafary, "Development of a scoring system for assessment of outcome of early undifferentiated inflammatory synovitis," Joint Bone Spine, vol. 75, no. 2, pp. 155-162, 2008.

[39] G. Moxley and H. J. Cohen, "Genetic studies, clinical heterogeneity, and disease outcome studies in rheumatoid arthritis," Rheumatic Disease Clinics of North America, vol. 28, no. 1, pp. 39-58, 2002.

[40] G. T. Nepom, “Genetics: preface," Rheumatic Disease Clinics of North America, vol. 28, no. 1, pp. 11-12, 2002.

[41] M. L. L. Prevoo, M. A. van't Hof, H. H. Kuper, M. A. van Leeuwen, L. B. A. van de Putte, and P. L. C. M. van Riel, "Modified disease activity scores that include twenty-eightjoint counts: development and validation in a prospective 
longitudinal study of patients with rheumatoid arthritis," Arthritis and Rheumatism, vol. 38, no. 1, pp. 44-48, 1995.

[42] H. Mäkinen, P. Hannonen, and T. Sokka, "Definitions of remission for rheumatoid arthritis and review of selected clinical cohorts and randomised clinical trials for the rate of remission," Clinical and Experimental Rheumatology, vol. 24, no. 6, supplement 43, pp. S22-S28, 2006.

[43] M. Soubrier, D. Zerkak, L. Gossec, X. Ayral, C. Roux, and M. Dougados, "Which variables best predict change in rheumatoid arthritis therapy in daily clinical practice?" Journal of Rheumatology, vol. 33, no. 7, pp. 1243-1246, 2006.

[44] J. Fransen, M. C. W. Creemers, and P. L. C. M. van Riel, "Remission in rheumatoid arthritis: agreement of the disease activity score (DAS28) with the ARA preliminary remission criteria," Rheumatology, vol. 43, no. 10, pp. 1252-1255, 2004.

[45] S. Reneses, L. Pestana, A. Fernandez-Suarez et al., "A recent onset inflammatory polyarthritis register in Spain: factors that predict remission," Scandinavian Journal of Rheumatology, vol. 36, no. 5, pp. 378-385, 2007.

[46] J. L. Caro-Oleas, A. Fernández-Suárez, S. Reneses, C. Porrino, A. Núñez-Roldán, and I. Wichmann, "Evaluation of third generation anti-CCP antibodies in the diagnosis of rheumatoid arthritis from undifferentiated polyarthritis after 4 years of follow-up," Clinical and Experimental Rheumatology, vol. 26, no. 3, pp. 461-463, 2008.

[47] J. Luis Caro-Oleas, A. Fernández-Suárez, S. Reneses, C. Porrino, A. Núñez-Roldán, and I. Wichmann, "Diagnostic usefulness of a third-generation anti-cyclic citrulline antibody test in patients with recent-onset polyarthritis," Clinical Chemistry and Laboratory Medicine, vol. 45, no. 10, pp. 13961401, 2007.

[48] W. N. Kelley, E. D. Harris, S. Ruddy, and C. B. Sledge, Eds., Textbook of Rheumatology, WB Saunders, Philadelphia, Pa, USA, 6th edition, 2001.

[49] V. P. K. Nell, K. P. Machold, T. A. Stamm et al., "Autoantibody profiling as early diagnostic and prognostic tool for rheumatoid arthritis," Annals of the Rheumatic Diseases, vol. 64, no. 12, pp. 1731-1736, 2005.

[50] S. M. van der Kooij, J. K. de Vries-Bouwstra, Y. P. M. GoekoopRuiterman et al., "Limited efficacy of conventional DMARDs after initial methotrexate failure in patients with recent onset rheumatoid arthritis treated according to the disease activity score," Annals of the Rheumatic Diseases, vol. 66, no. 10, pp. 1356-1362, 2007.

[51] S. L. Hider, A. J. Silman, W. Thomson, M. Lunt, D. Bunn, and D. P. M. Symmons, "Can clinical factors at presentation be used to predict outcome of treatment with methotrexate in patients with early inflammatory polyarthritis?" Annals of the Rheumatic Diseases, vol. 68, no. 1, pp. 57-62, 2009.

[52] A. van der Heide, J. W. G. Jacobs, J. W. J. Bijlsma et al., "The effectiveness of early treatment with "second-line" antirheumatic drugs: a randomized, controlled trial," Annals of Internal Medicine, vol. 124, no. 8, pp. 699-707, 1996.

[53] S. Reneses, M. F. González-Escribano, A. Fernández-Suárez et al., "The value of HLA-DRB1 shared epitope, -308 tumor necrosis factor- $\alpha$ gene promoter polymorphism, rheumatoid factor, anti-citrullinated peptide antibodies, and early erosions for predicting radiological outcome in recent-onset rheumatoid arthritis," Journal of Rheumatology, vol. 36, no. 6, pp. 1143-1149, 2009. 


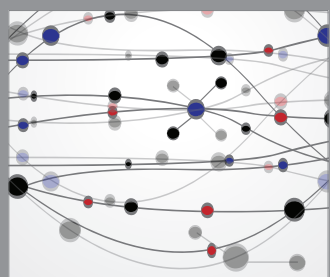

The Scientific World Journal
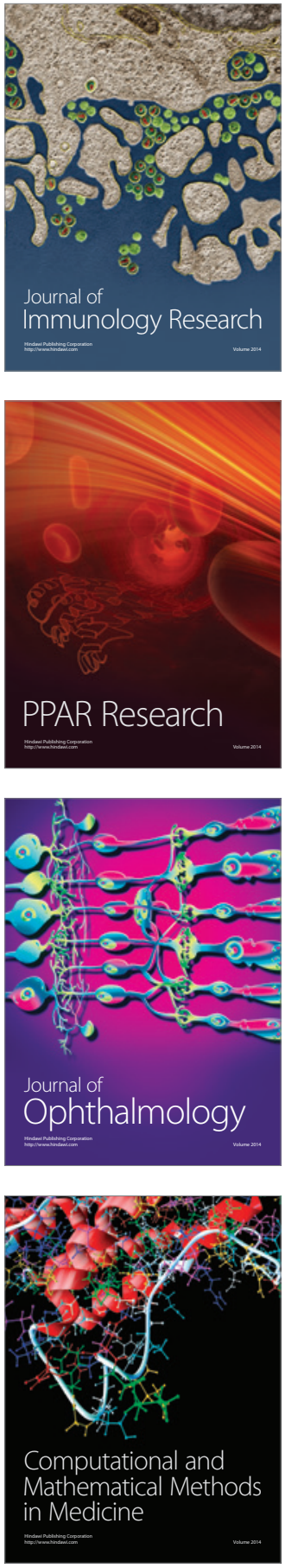

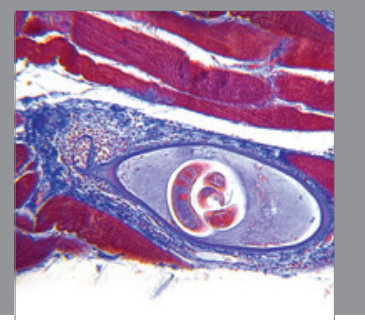

Gastroenterology

Research and Practice
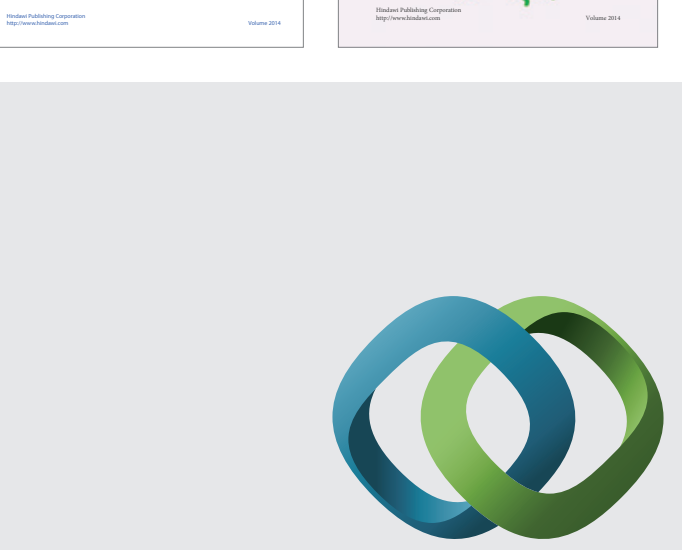

\section{Hindawi}

Submit your manuscripts at

http://www.hindawi.com
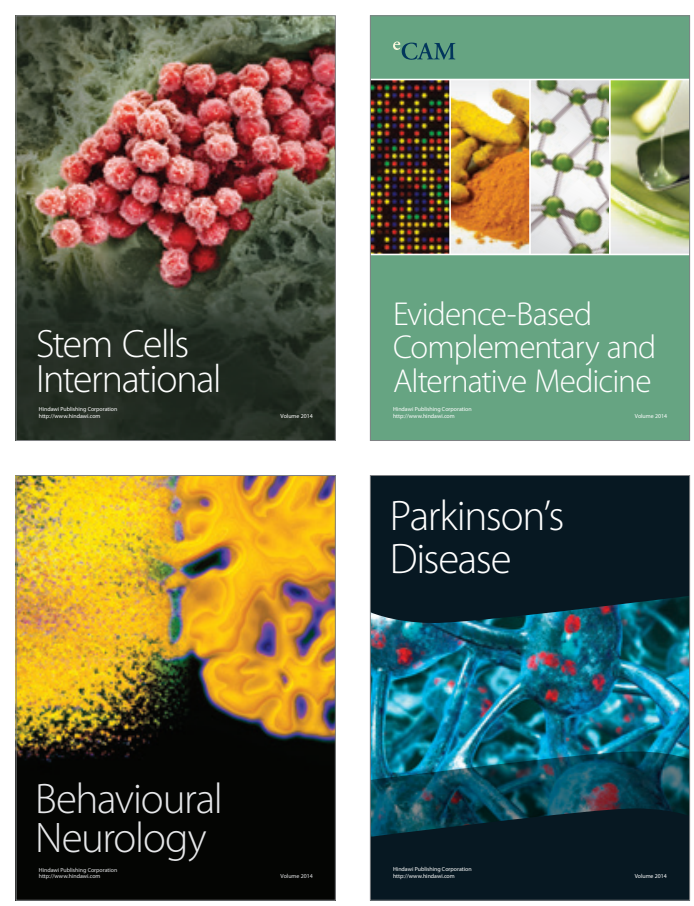

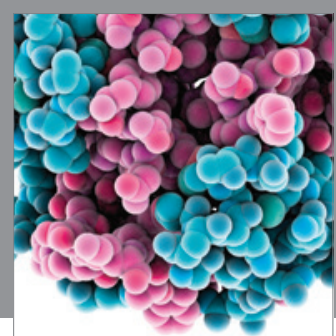

Journal of
Diabetes Research

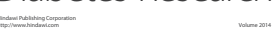

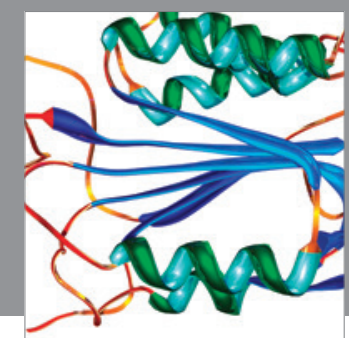

Disease Markers
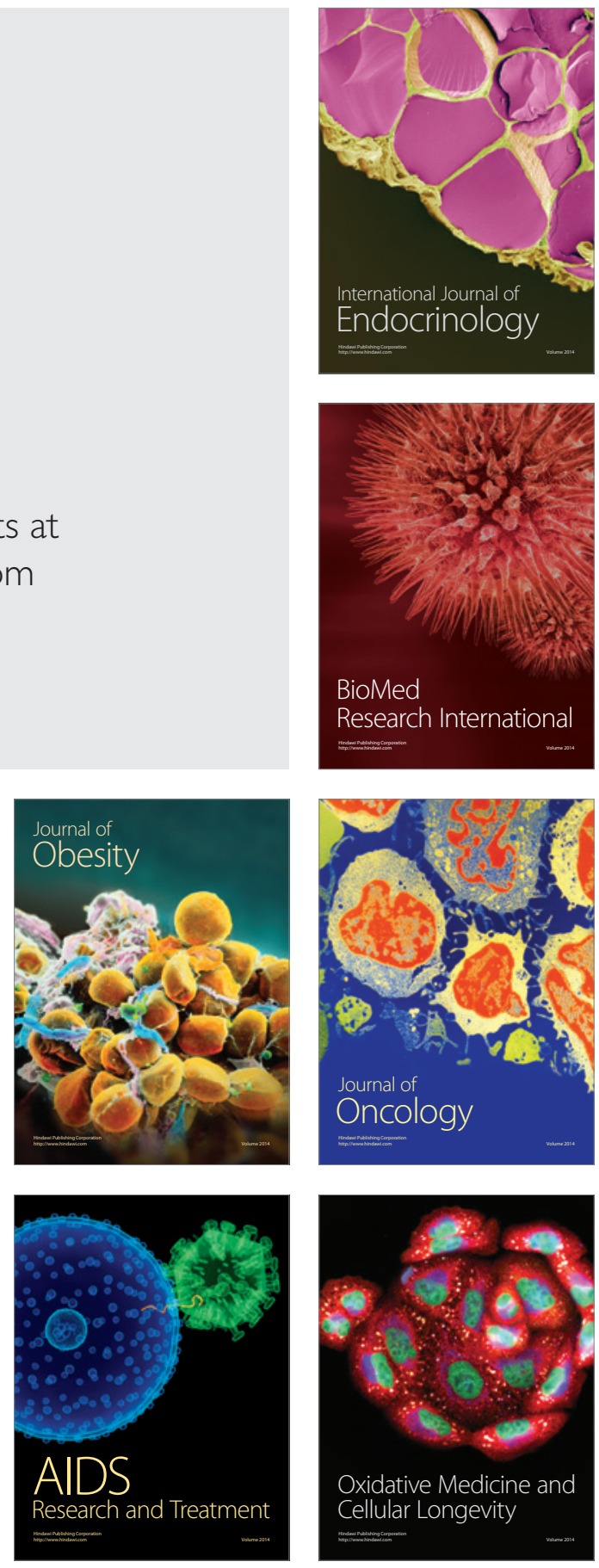